\title{
Development of Networked Virtual Experiment System Based on Virtual Campus
}

\author{
Tian-tai GUO \\ Dept. of Measurement \& Control Technology and Instrumentation, China Jiliang University, Hangzhou, P.R. China \\ Email: guotiantai@cjlu.edu.cn \\ Lin GUO and Dong-sheng LI \\ Dept. of Measurement \& Control Technology and Instrumentation, China Jiliang University, Hangzhou, P.R. China \\ Email: \{guolin, lidongsheng\}@163.com
}

\begin{abstract}
China's higher education has been going through a period of rapid expansion in undergraduate population, and this means a much heavier demand on teaching resources such as laboratories, experiments, teaching staff, etc., which cannot possibly be made available all of a sudden. To deal with this situation, we found virtual reality (VR)mtechnology very helpful. Virtual reality (VR) has found many applications in education; and the resources of virtual education such as virtual campus, virtual laboratory etc. are used more and more widely, especially in the field of higher education. But so far virtual campus was mainly regarded as a means of image exhibition, and virtual laboratories were no more than 2D display of experimental processes and equipments. To make better use of these resources, this paper puts forward the concept of networked virtual experiment systems based on virtual campus by combining the virtual laboratory and virtual campus with the technique of LAN (Local area network), and establishes its theoretical model. Finally, a networked virtual experiment system based on virtual campus is developed using VRML and 3DSMAX. Networked virtual experiment system based on virtual campus has a promising future for various applications in higher education.
\end{abstract}

Index Terms-Virtual reality (VR); Virtual campus; Virtual laboratory; Networked virtual experiment system; Virtual reality modeling language (VRML)

\section{INTRODUCTION}

China's higher education has been going through a period of rapid expansion in undergraduate population, and is making transition from elitist education to mass higher education. In the year 1999, we saw the beginning of continual and rapid increasing of students enrolled in universities in China, and the gross enrolment rate has reached about $23 \%$ in 2007. It can be seen from Table I that the number of college graduates in China has increased about 300\% since 2002.

While attributing a lot to China's national economy and development of higher education, this increasing of college undergraduates has undoubtedly posed many

Manuscript received January 4, 2009; revised June 5, 2009; accepted July 12, 2009.
TABLE I. NUMBER OF COLLEGE GRADUATES IN CHINA SINCE 2002

\begin{tabular}{|c|c|}
\hline Year & Number of college graduates \\
\hline 2002 & $1,450,000$ \\
\hline 2003 & $2,120,000$ \\
\hline 2004 & $2,800,000$ \\
\hline 2005 & $3,380,000$ \\
\hline 2006 & $4,130,000$ \\
\hline 2007 & $4,950,000$ \\
\hline 2008 & $5,600,000$ \\
\hline
\end{tabular}

challenges for the administrators of universities and colleges, among which the most prominent two are the shortage of teaching resources and fiercer competition in a labor market which did not expand simultaneously. In fact, these two factors are interconnected: for college students majoring in specialties with engineering backgrounds, it is essential for them to obtain engineering practices and experiments in laboratories, and only through this way can they be expected to be competitive after graduation.

Considering the fact that in the past several years China's national economy has been increasing steadily, and this year the economical situation has apparently deteriorated (with an estimated increase rate of only about $8.8 \%$ ), it can easily be seen that the employment situation for college graduates in China is really very severe.

In a word, the expansion in undergraduate population and harsh competition in the labor market $_{2}$ demands students to be more capable, and this means a much heavier demand on teaching resources such as laboratories, experiments, teaching staff, etc., which cannot possibly be made available all of a sudden. To deal with this situation, we found that the technology of virtual reality (VR) very helpful, and puts forward the concept of networked virtual experiment system based on virtual campus, which is formed by combining the virtual laboratory and virtual campus with the technique of LAN (Local area network).

\section{VIRTUAL REALITY}


In recent years, virtual reality (VR) technology has attracted more and more attention. VR has the advantages of virtual environment, vision system and simulation system, in which users can have the experience of being immerged in 3D environment and interacting with virtual objects in it with the aid of head-mounted display (HMD), eyeglasses, data gloves, trackers and other peripherals, and the users feel like they are really in the virtual environment[1]. VR has the remarkable features of immersion, interaction, imagination, which were referred to as "3Is" by G. Burdea[2]. With the development of computer technology, the cost of VR peripherals and systems has been significantly reduced, and VR has been utilized in many fields such as spaceflight, aviation, military training, medical treatment, industrial design, etc.. In addition, VR also shows great potential in the field of education[3]-[7].

Combining virtual reality with education can provide a novel, convenient and flexible platform for modern teaching activities, and is good for elucidating different learning concepts and theories, especially for the integration of multiple learning concepts[5]. As is well known, universities in China has been faced with the problem of a drastically increased number of enrolled students in campus, while at the same time its facilities and faculties cannot possibly follow this trend immediately. Here VR can play an irreplaceable role. Applying VR in education can make up for the lack of facilities and faculties, and supplies vivid and economical ways of teaching which is accessible for any students who have interests in it. VR can be very helpful in improving teaching quality due to its distinct features of "3Is".

So far as VR's application in education is concerned, VR was mostly used in the form of virtual campuses and virtual laboratories. However, the existing virtual campuses and virtual laboratories are developing on two parallel tracks, i.e., they are mostly separated, so the users can only enjoy the advantages of either virtual campus or virtual lab, but not at the same time. To improve this situation, this paper puts forward the concept of networked virtual experiment system based on virtual campus by combining the virtual laboratory and virtual campus with the technique of LAN (Local Area Network), establishes its theoretical model, and finally develops a networked virtual experiment system based on virtual campus using VRML and 3DSMAX. Students can navigate in the virtual campus and visit the virtual $3 \mathrm{D}$ laboratories freely, or practice every kind of experiment in the virtual laboratories, and get the experiences of being really in the laboratories and conducting experiments themselves, thus obtaining a better understanding of the subjects concerned.

\section{VIRTUAL EXPERIMENT}

The term "virtual experiment" can cover a wide range of technologies and instruments from 2D simulation software, virtual instruments, etc. to 3D virtual environments. As is shown in Fig.1, virtual experiment has undergone several changes in its evolution.

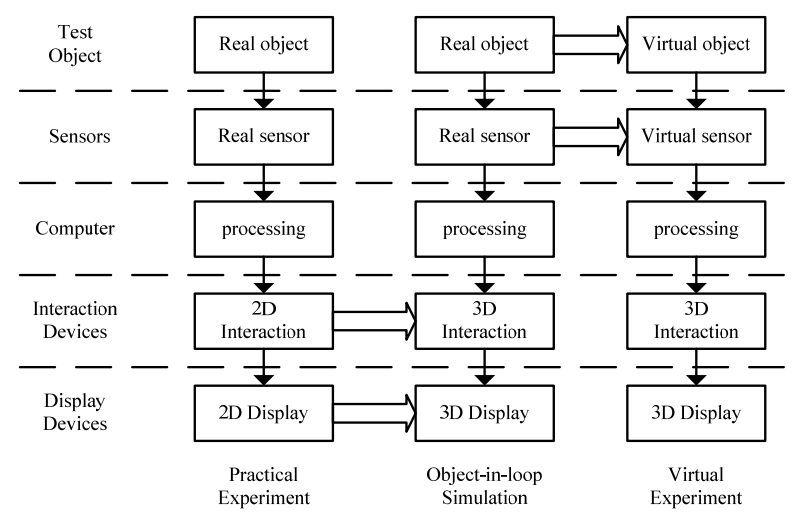

Figure 1. Progress of virtual experiment

First, the test object under experiment has shown a trend of virtualization, which means that in many cases the test objects are replaced by virtual objects generated with computer software, instead of real objects.

Second, the sensors are also becoming virtualized, which means traditional physically real sensors are sometimes replaced by virtual sensors generated with computer software.

Third, the interaction devices adopted have developed rapidly from traditional $2 \mathrm{D}$ interaction devices such as keyboards and mouse to 3D interaction devices such as joysticks, space balls, trackers, data gloves, data suit, etc., which supply more user-friendly interaction interface between the users and computers, and make immersion into virtual environments not only possible but also practical.

Fourth, the display devices have shown a trend of transition from 2D display (typically plane display like CRT) to 3D display such as head-mounted display (HMD) or wide-screen display, which are more natural to the users.

Besides the above-mentioned four points, the central part of any virtual experiment system is the computer, which has also been developing rapidly, with larger storage, faster speed and better processing capabilities.

By substituting real objects with virtual (imaginary) objects, and real sensors with virtual sensors, VR-based virtual experiment systems can be readily constructed, and the basic idea is first to generate a virtual experiment environment with computer software supported by appropriate computer hardware and VR peripherals in accordance with specific applications, in which virtual reality (VR) serves not only as an interface but also as an interaction tool between the user and the virtual experiment environment, and then the experiment processes are interactively planned, optimized and simulated in a virtual experiment environment, while intermediate and final experiment results are visualized, analyzed and replayed in dynamic 3D forms.

Fig. 2 is the simulation model of virtual experiment, which shows the corresponding relationship between the real (physical) world and virtual world, and is comprised 
of four main parts: the real (physical) world, the virtual world, virtual reality interface, and the user. The real (physical) world is the world in which the physical experiment is performed, while the virtual world is the computer-generated counterpart of the real (physical) world. The mapping between the two worlds is through the processes of modeling and validation. The virtual reality interface supplies an interface between the two worlds, so that information exchange can be conducted between them, and the user manages the virtual world through the virtual reality interface.

Modeling

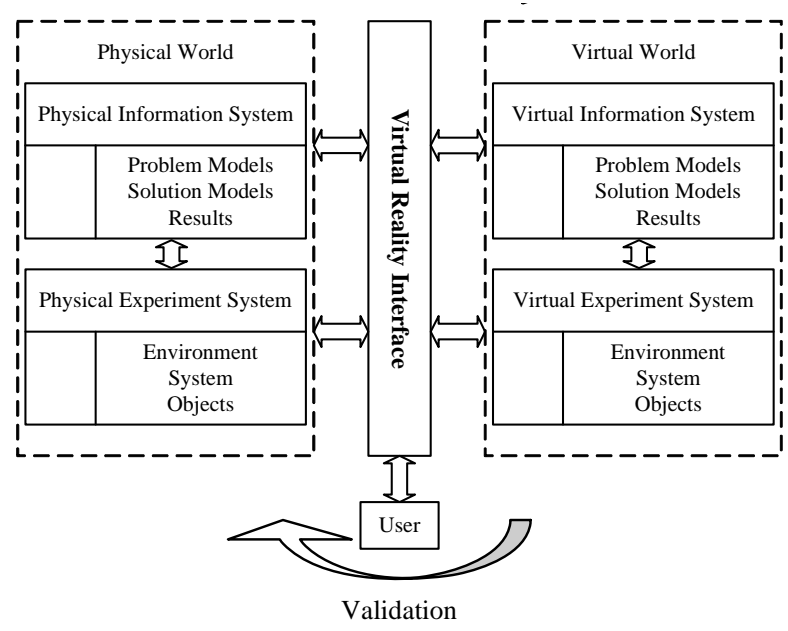

Figure 2. Progress of virtual experiment

The physical world is made up of the following components: 1) Physical information system, including problem models, solution models, results, etc. 2) Physical experiment system, such as the developing environment, system, objects, etc. Correspondingly, the virtual world is

TABLE II. NUMBER OF COLLEGE GRADUATES IN CHINA SINCE 2002

\begin{tabular}{|c|c|c|}
\hline & With real test object & Without real test object \\
\hline Experiment & Physical experiment & $\begin{array}{c}\text { Complete VR-based } \\
\text { experiment }\end{array}$ \\
\hline Simulation & $\begin{array}{c}\text { Object-in-loop } \\
\text { simulation }\end{array}$ & $\begin{array}{c}\text { VR-based experiment } \\
\text { and simulation }\end{array}$ \\
\hline
\end{tabular}

also made up by two main components: virtual information system and virtual experiment system.

Virtual experiments can supply an effective way of teaching college students whose specialties have engineering backgrounds, since the engineering-related equipments, sensors and experiments have been studies thoroughly, thus making their virtualization very convenient. With the adoption of virtual reality (VR) as its newest stage, virtual experiment can be both interesting and useful. Flexibility and economy are the two most prominent features of virtual experiment systems.
Virtual experiments can be used to simulate available experiments for tutorial and training purposes, or to design new experiment equipments to show the principles and configurations of the equipments under design, or eventually to perform virtual experiments completely in a virtual experiment environment on the basis of theoretical modeling and simulation. Accordingly, the virtual experiment environment can either be a replica of actual world scenes, or any imagined or designed environment generated by computer. Accordingly, depending on the function and whether real (physical) test objects exist in experiments, virtual experiment systems can be classified into four categories (as shown in Table II): physical experiment, object-in-loop experiment simulation, VRbased experiment and simulation, and complete VRbased experiment. The first two categories are the traditional way of conducting experiment and simulation, while the latter two are the trend of experiment and simulation technologies.

Virtual experiment also has its disadvantages, and at the top is the initial cost to construct a virtual experiment system. VR equipments like space balls, data gloves and possibly head-mounted displays (HMDs) or wide-screen display are indispensable besides computer with high performance and appropriate system software and application software. Other disadvantages include the training of skilled personnel, technical support, sophisticated modeling, and sometimes the lack of product information. But once the system is setup, it can be easily adjusted for other similar purposes. This justifies its initial cost.

It must also be noted that virtual experiments in essence is a kind of computer simulation, so the accuracy of virtual experiments is dependent on many factors, such as the accuracy of modeling, computation capabilities, function requirements, etc. To help the evaluation and validation of experiment results, practical experiments sometimes are still necessary.

\section{VIRTUAL CAMPUS}

Virtual campus is the rendering of college campus in the form of a $3 \mathrm{D}$ virtual environment, which is usually based on a real campus counterpart, but not necessarily always so. It's a digitized virtual space of an existing or imagined campus, and is mainly utilized as a means of image exhibition or campus design. Compared with conventional propaganda tools, it is much more convenient and economical, and has much higher accessibility. So it's not strange that many universities have set up their own virtual universities and virtual campuses. Take China as an example, many universities have done this, for example, Beijing University of Aeronautics and Astronautics, Zhejiang University, Tianjin University, to name just a few. Among them many have developed virtual campuses by using virtual reality modeling language (VRML), which is a programming software and can be used on personal computers very conveniently, thus greatly reducing the cost of system development. With the rapid development of information technology and online education, and the 
popularity of broad band technology, virtual campuses have attracted a lot of attention and has seen many applications, and has brought about many changes in teaching methods and ideas.

The structure of virtual campus can be very complicated, but at the bottom of it is the structural diagram of virtual campus. As is shown in Fig. 3, a virtual campus is a network of interconnected nodes which are generated by computer and rendered in 3D forms. As the main and only interface, the 3D environment includes all the scenes of architectures, animations, backgrounds, lakes, etc.

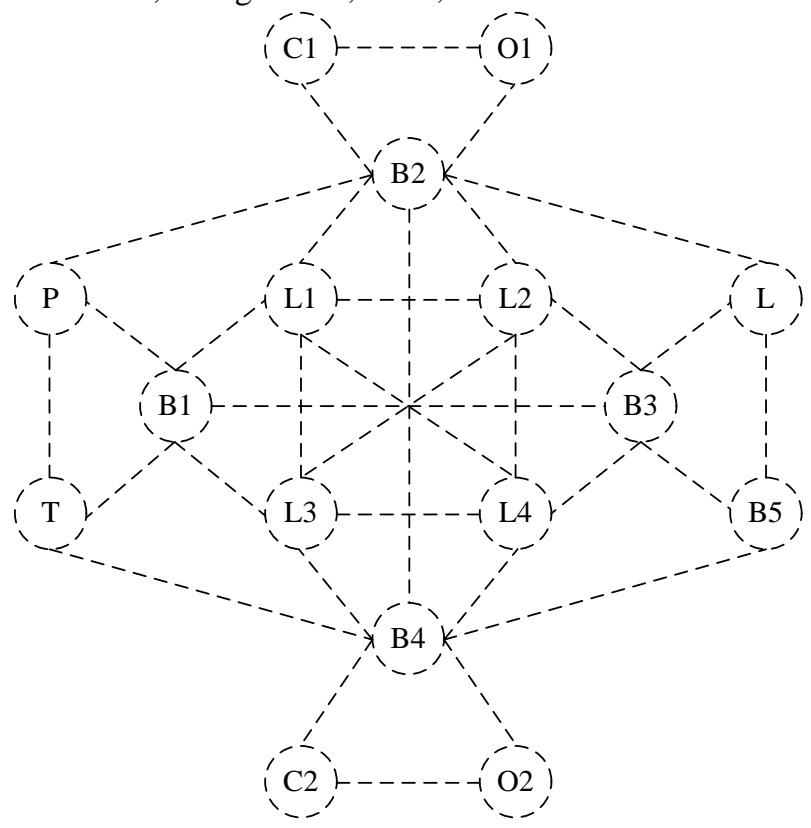

Figure 3. Structural diagram of virtual campus

Ln: Laboratories B: Building C: Classroom On: Office L: Lake

\section{P: Pavilion T: Tree}

Logically, the structure of a virtual campus can be divided into a multi-level structure as is shown in Fig. 4, which shows four levels. On top is the whole campus, and below they are the geometrical models, kinetic models and dynamic models, which are accordingly subdivided into more detailed description of the objects and properties. The levels can be expanded or cut short according to the requirement of the system.

With the popularity of online education, virtual campuses show its disadvantages: users can only browse and visit the virtual environment of the campus, but cannot do much to make full use of it. Reality, interaction and scenario are the most fascinating features of virtual reality; however, most existing virtual campuses support only simple functions like navigation, which even reduces its appeal as a means of advertising. So, virtual campus has to be improved to make it more practical and useful.

\section{NETWORKED VIRTUAL EXPERIMENT SYSTEM BASED ON VIRTUAL CAMPUS}

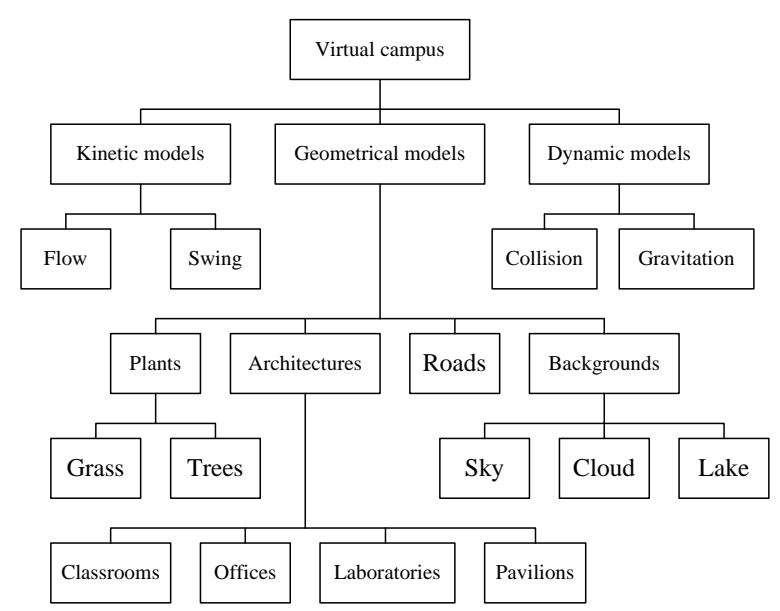

Figure 4. Tree structure of virtual campus

\section{A. Virtual Experiment Systems}

Virtual experiment systems are applied systems for the simulation of processes of almost all kinds of experiments. So far, it can be subdivided into two categories: a) Virtual experiment systems in 2D forms[6][7], this includes many software-based 2D experiment and training platforms, such as the widelyused virtual instruments (VI); b) Virtual experiment systems in 3D forms, which utilizes virtual reality (VR) to enhance the visual effect and interaction between users and the systems[8][9]. Virtual instrument has been a hot subject in recent years, but its 2D interface made it less popular with young students.

Generally speaking, the virtual experiment systems are most often a replication of a real experiment, and the virtual experiments take place in a simulated environment, either in the form of 2D blocks or 3D virtual environment, with specific algorithms behind the scenes to monitor the choices and operations of the user and control the processes of experiments.

Compared with 2D experiment systems, the 3D virtual experiment systems are more attractive to young students, and can greatly inspire students' interests in learning, enrich the contents of experimental education, economize the expense of colleges, and strengthen the interaction between students and experimental equipments and objects.

With the development of network technology, the virtual equipments and instruments can be connected with equipments and instruments in the real world, or receive signals from the real world, thus forming many networked virtual experiment systems. But so far, most networked virtual experiment systems are based on 2D virtual instruments, which are developed using programming languages such as MatLAB, LavVIEW, LabWindows, HP VEE etc.[10][11]. Since the 2D forms are not vivid, young students often prefer to do practical operations rather than operate on the virtual instruments. On the other hand, many networked virtual reality systems are mainly used for training purposes in military and industrial applications.

The structural diagram of existing networked virtual experiment systems is also very complicated. However, 
for easy discussion, it can be simply shown as Fig. 5, in which virtual laboratories are connected to each other, but be supervised by the administrator. Users can access every virtual laboratory through the network.

\section{B. Basic Idea of Networked Virtual Experiment System based on Virtual Campus}

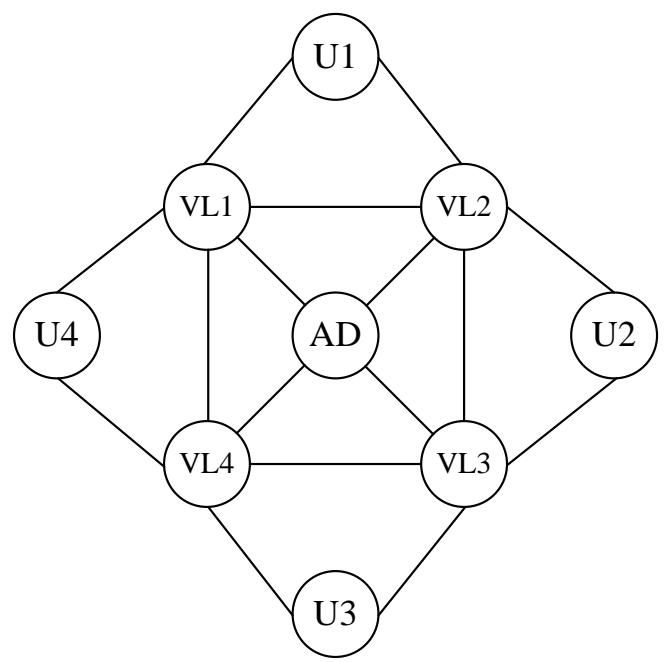

Figure 5. The Structural diagram of networked virtual experiment system

VL: Virtual laboratoies U: Users AD: administrator

Since the functions of most existing virtual campuses and virtual laboratories are separated, some potential functions of both virtual campus and virtual laboratories are not used so far. To make the virtual campus and virtual laboratories more convenient and economical, this paper combines the function of navigation and interaction of virtual campus and $3 \mathrm{D}$ virtual laboratories together to establish a networked virtual experiment system based on virtual campus. This system can realize the combination and share of the experiment teaching resources which can be browsed and used freely, and benefit to the development and administration of the experimental education.

The networked experiment system based on virtual campus is established in the $3 \mathrm{D}$ form. In the $3 \mathrm{D}$ environment, users can observe the processes and instruments much better and more flexible than 2D rendering form. During the process of experiment, the details of the experiments, structures of instruments, results, etc. are all observable through omnidirectional change of vision. The 3D rendering form excels 2D form either in experimental vitality or reality, and is much fit for guiding students to experiment.

\section{Models of Networked Virtual Experiment System based on Virtual Campus}

The basic idea of networked virtual experiment system based on virtual campus is mix the functions of virtual laboratories and network server by introducing LAN. The mapping model of networked virtual experiment system based on virtual campus is as shown in Fig. 6. Since the network has already been used in the virtual experiment system, the model of networked virtual experiment system based on virtual campus embodies the combination of the networked experiment system and virtual campus, and its model is established on the basis of the mapping model. The topographic model of networked virtual experiment system based on virtual campus is as shown in Fig. 7. The nodes of laboratories and virtual laboratories are combined to be the networked virtual laboratories. In a certain virtual campus, users can either enter any virtual laboratory to operate every kind of experiment conveniently and freely or navigate the virtual campus.

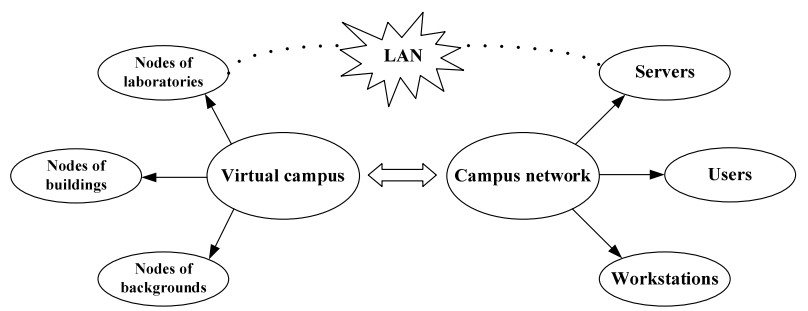

Figure 6. Mapping model of networked virtual experiment system based on virtual campus

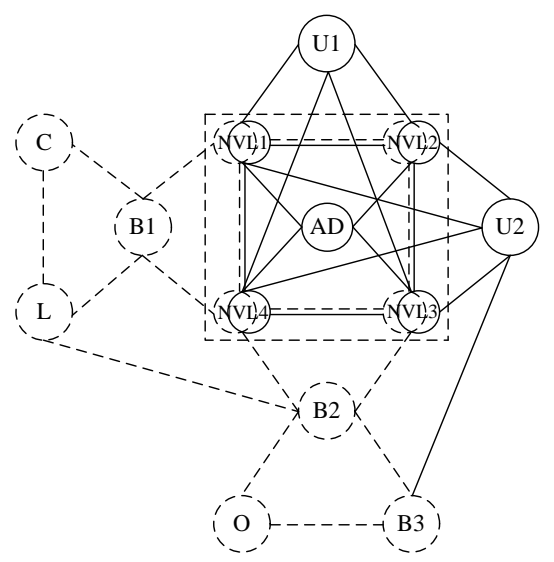

Figure 7. The topographical model of networked virtual experiment system based on virtual campus

\footnotetext{
NVL: Networked virtual laboratories based on virtual campus U: Users B: Buildings O: Office C: Classroom L: Lake AD: Administrator
}

The theoretical model of networked virtual experiment system based on virtual campus is shown in Fig. 8, which is comprised of two major parts which can be subdivided into five inter-dependent functional layers either. The five layers of virtual experiment system include:

1) Perception layer: this is the layer which supplies the user with a virtual experimental environment, and the user can interact directly with the virtual environment and the virtual experiment.

2) Function layer: this layer consists of the basic functions of virtual experiment system, including design, simulation, training, display, etc. 
3) Algorithm layer: this layer integrates the algorithms necessary for the operation of virtual experiment system, such as planning algorithm, phenomenon algorithm, data processing algorithm.

4) Information layer: this layer includes the information of experimental description, demonstration, display, etc.

5) Physical layer: this layer comprises the hardware of the virtual environment such as experimental instruments, tables, chairs, etc.

While the counterpart five layers of network include application layer, data layer, communication layer, protocol layer, and physical layer. The dashed block is the established networked virtual experiment system based on virtual campus. The networked experiment system is connected with the LAN through the applied software. Users can enter any virtual laboratory to operate experiments as long as the corresponding node of virtual laboratory is found.

\section{DEVELOPMENT OF NETWORKED EXPERIMENT SYSTEM}

\section{A. Virtual Reality Modeling Language(VRML)}

VRML(virtual reality modeling language) is one of the most popular development tools for establishing the 3dementional environment. VRML introduces the interactive 3D rendering form into the World Wide Web, and it is a multi-platform used modeling language. VRML uses the node as the basic unit, and defines the common descriptive languages of 3D application system such as light source; animation, changing of levels, etc., and it have the function of simply description of the behavior characteristics. VRML has the advantages of expansible, multi-platform, interaction, etc. [11].

\section{B. Geometrical Modelling}

Geometrical modeling is the foundation of VR systems, and we adopts 3DS MAX to generate 3D geometrical models in virtual experiment systems.

Virtual Experiment System

Network

\begin{tabular}{|c|c|}
\hline $\begin{array}{l}\text { Perception } \\
\text { Layer }\end{array}$ & $\begin{array}{l}\text { Applications } \\
\text { Layer }\end{array}$ \\
\hline Function Layer & $\overline{\text { Data }} \overline{\text { Layer }}$ \\
\hline $\begin{array}{l}\text { Algorithm } \\
\text { Layer }\end{array}$ & $\begin{array}{c}\text { Communication } \\
\text { Layer }\end{array}$ \\
\hline $\begin{array}{l}\text { Information } \\
\text { Layer }\end{array}$ & Protocol Layer \\
\hline Physical Layer & Physical Layer \\
\hline
\end{tabular}

Figure 8. The theoretical model of networked virtual experiment system based on virtual campus
VRML uses nodes to establish virtual scenes. However, using nodes to design models is not very convenient, and is difficult to design complicated models. However, the 3DSMAX can make up for the disadvantages of VRML. 3DSMAX is mainly used in the fields of architecture design and $3 \mathrm{D}$ animations. The models designed by 3DSMAX have sound level feeling, and are easy controlled. Although, as to the expression of details of geometric model, 3DSMAX is more inferior than Pro/E and other pro modeling software. While in the virtual campus and virtual experiment which mainly focus on the feeling of interaction and immersion, the detail is not a leading factor, so, the simply-operated modeling software 3DS MAX is popular in the design of virtual campus and virtual experiment. Fig. 9 shows the models designed

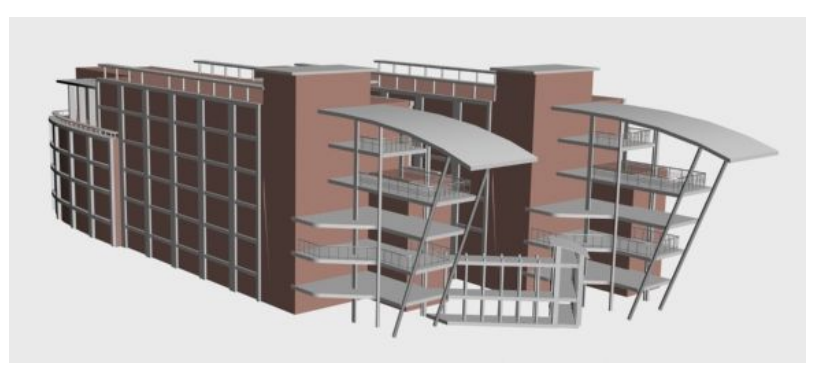

(a) Model of virtual teaching building

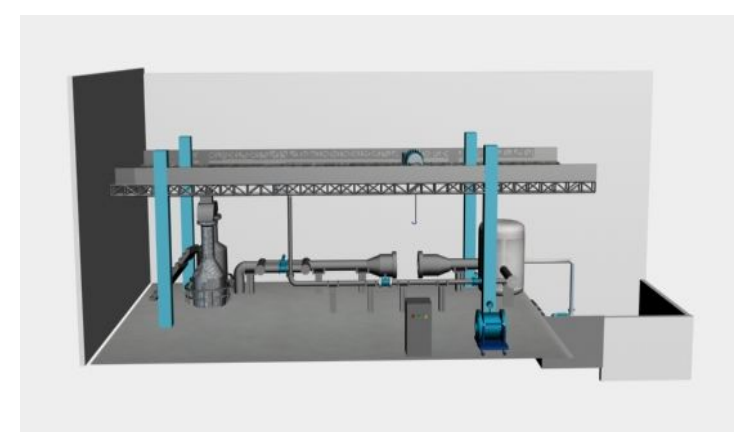

(b) Model of virtual equioument

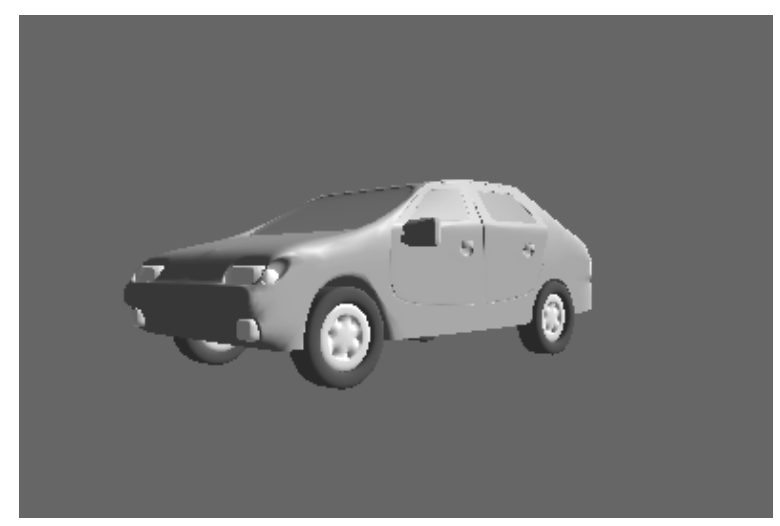

(c) Model of virtual vehicle

Figure 9. The building and experimental instrument designed by 3DS MAX 
with 3DS MAX, in which Figs. 9 (a), 9(b) and 9(c) show the geometrical models of a virtual teaching building, a virtual equipment, and a virtual vehicle, respectively.

\section{Kinetic Modelling}

In performing virtual experiments, it is important to make the virtual experiments look real, which requires more than mere geometrical modeling.

Kinetic modeling supplies the virtual experiment with such information as to make the trajectiles of the movements of the virtual objects in the virtual experiment environment look natural and coherent.

Fig. 10 shows an example of a kinetic model, in which the trajectile of moving vehicle is subdivided into several sections, and in the places where the curvature of the curve is large, the sampling frequency is high, while in the places where the curvature is small, the sampling frequency is low. In this way, the coordinates needed to be stored are those of the flexure points and the sampled points. This reduces the quantity of simulation data and causes much convenience for the processing of data, without causing much damage to the efficiency and vivacity of the virtual experiment system.

Suppose that the coordinates of flexure points A, B in Fig. 10 are $\left(\mathrm{x}_{1}, \mathrm{y}_{1}, \mathrm{z}_{1}\right)$ and $\left(\mathrm{x}_{2}, \mathrm{y}_{2}, \mathrm{z}_{2}\right)$ respectively, and a point $C$ lies within them, with a distance $d$ from flexure point $\mathrm{A}$, then the coordinates of point $\mathrm{C}$ can be readily obtained as:

$$
\begin{aligned}
& x=x_{1}+\frac{d}{l}\left(x_{2}-x_{1}\right) \\
& y=y_{1}+\frac{d}{l}\left(y_{2}-y_{1}\right) \\
& z=\frac{z_{2}-z_{1}}{y_{2}-y_{1}}\left(y-y_{1}\right)+z_{1}
\end{aligned}
$$
B:

Where $\mathrm{l}$ is the distance between flexure points $\mathrm{A}$ and

$$
l=\sqrt{\left(y_{2}-y_{1}\right)^{2}+\left(x_{2}-x_{1}\right)^{2}}
$$

Through these calculations, the trajectile can be simulated with satisfactory results.

\section{Dynamic Modelling}

Dynamic modeling is the modeling of the dynamic behavior of the virtual experiment system, which requires thorough understanding of the objects under research, and mathematical models often appear as differential equations.

Fig. 11 shows an example of a dynamic model of a vehicle suspension, which includes the physical properties such as vibration, material, stability, magnetic field, etc., and is essential for the success of virtual vehicle experiment systems, such as in the study of operational stability performances of vehicles.

In the dynamic model shown in Fig. 11, the suspension is regarded as a mass -spring-damper system, and the dynamic equations can be obtained as:

$$
\begin{aligned}
& m \ddot{z}=-k_{1}(z-q)+k_{1} a \theta-c_{1}(\dot{z}-\dot{q})+c_{1} a \dot{\theta}-k_{2}[z-q \\
& -(a+b) \phi]-k_{2} b \theta-c_{2}[\dot{z}-\dot{q}-(a+b) \dot{\phi}]-c_{2} b \dot{\phi} \\
& J \ddot{\theta}=k_{1}(z-q)-k_{1} a \theta \bullet a+c_{1}(\dot{z}-\dot{q}) a-c_{1} a \dot{\theta}-k_{2}[z-q \\
& -(a+b) \phi]-k_{2} b \theta \bullet b-c_{2}[\dot{z}-\dot{q}-(a+b) \dot{\phi}] b-c_{2} b \dot{\phi} \bullet b
\end{aligned}
$$

Where $m$ is mass of the suspension, $J$ is rotary inertia of the suspension, $\mathrm{z}$ denotes upward movement, $\theta$ denotes the counterclockwise rotation of the suspension, $q$

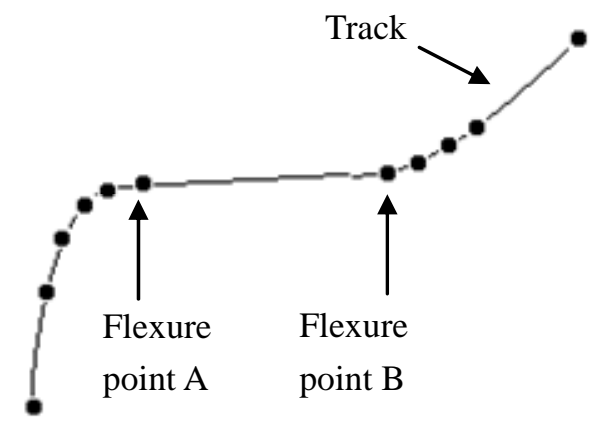

Figure 10. Example of a kinetic model

denotes the upward movement of the ground, $\phi$ denotes the counterclockwise rotation of the ground, $\mathrm{k} 1$ and $\mathrm{c} 1$ are the elastic coefficient and damp coefficient of the front part respectively, $\mathrm{k} 2$ and $\mathrm{c} 2$ are the elastic coefficient and damp coefficient of the rear part respectively.

Then the dynamic response of the suspension can be deduced on the bases of Eqs. (5) and (6), and the dynamic behavior of the virtual vehicle can then be calculated and displayed.

\section{E. Network as plaftorm of virtual experiments}

As has been discussed above, network plays an important role in networked virtual experiments systems, in which the network not only serves as the interconnecting element of the virtual experiment system, but also supplies a platform for all virtual experiments. Users can have access to virtual laboratories and virtual experiments through network, thus making a networked virtual experiments system practical. The users can perform tele-experiment education, data acquisition, navigating the virtual campus, and enter a certain virtual laboratory to operate every kind of experiment by clicking the corresponding node of the corresponding virtual laboratory. In the process of the virtual experiment, the experimental data, results and evaluation of the operations can be obtained in real time. The whole process of virtual experiment is implemented in a completely interactive and 3-dimentional virtual experiment environment. Users can choose different virtual laboratories to do different kinds of experiments according to the users' special needs and requirements.

\section{AN INSTANCE OF NETWORKED ViRTUAL EXPERIMENT SYSTEM}




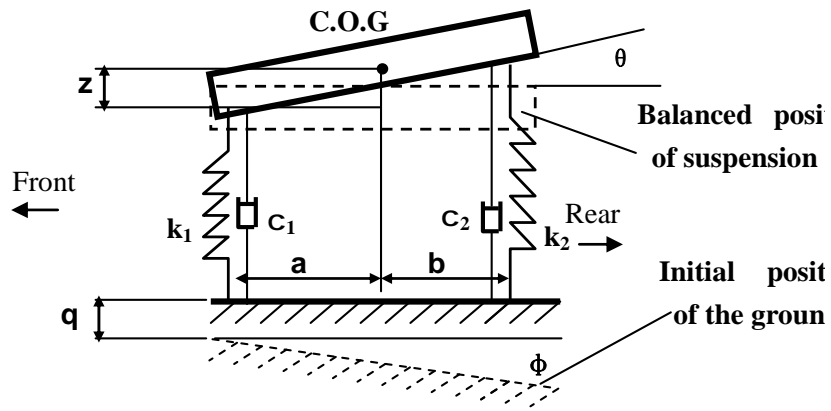

Figure 11. Dynamic model of a vehicle suspension

Networked virtual experiment systems based on virtual campus can serve very versatile tasks depending on the specific needs and requirements of the users. In out teaching and scientific researches, we have found networked virtual experiment systems based on virtual campus a very useful tool.

Fig. 12 shows a networked virtual experiment system based on the virtual China Jiliang University, in which a virtual ultrasonic NDT system was developed for operations and demonstrations.

In addition, user must register before entering the virtual laboratory system. It is convenient for administration of teaching. The novel system can be improved through the reflecting messages.

Networked virtual experiment system based on the virtual campus relies heavily on modeling.

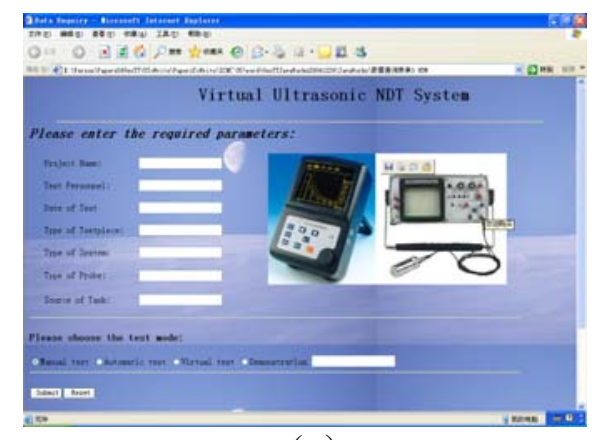

(a)

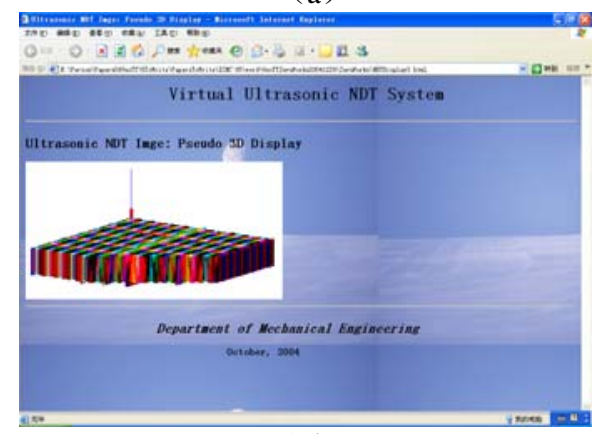

(b)

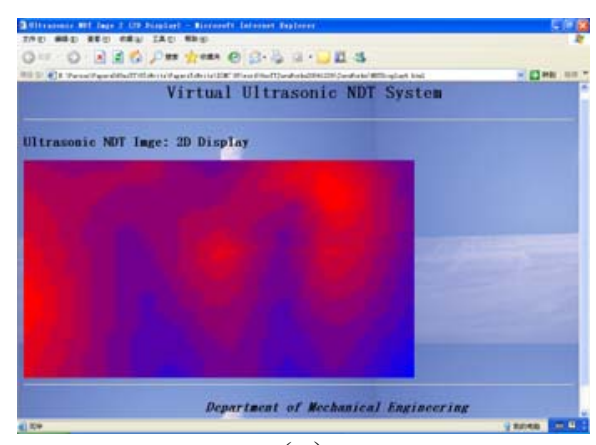

(c)

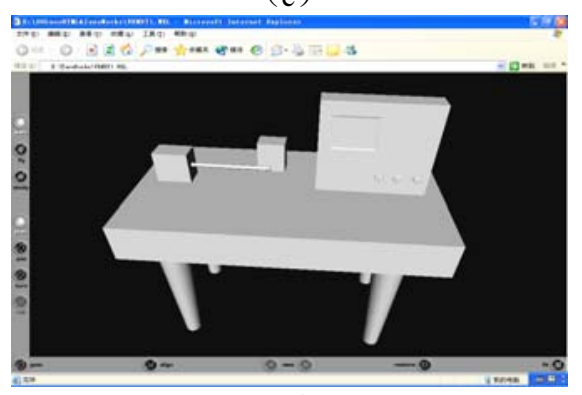

(d)

Figure 12. An example of networked virtual experiment system based on virtual campus

\section{CONCLUSION}

So far, the virtual campuses and virtual laboratories are widely used in higher education. However, there are still some issues are exited in the both of them, such as single function, 2D rendering form, the reality of experiment is not strong, etc.. To settle these issues, this paper combines with the virtual campus and virtual laboratory through introducing LAN to establish a networked virtual experiment system based on virtual campus. A model system of networked virtual experiment system based on virtual campus is established on the basis of theoretical researches. Besides solving the exited issues of virtual campuses and virtual laboratories, this paper also improves the function of them, and can stimulate the students' interests in learning. The established model system works sound, and gets the good effects. The networked virtual experiment system based on virtual campus is a good reference to establish the multifunctional platform of education, and has the positive effects of promoting the application of virtual reality in the field of education.

\section{REFERENCES}

[1] Tiantai GUO, Xiaojun ZHOU, Genxing ZHU, "APPLICATION OF CBR IN VR-BASED TEST AND SIMULATION SYSTEM,” Proc. of 2003 International Conference on Machine Learning and Cybernetics. Xi-an, China. 2-5 November 2003, pp. 2337-2340.

[2] Burdea G, Coiffet P, "Virtual Reality Technology (2nd Edition),” Wiley-IEEE Press, June 2003.

[3] Teresa Monahan, Gavin McArdlea, Michela Bertolottoa, "Virtual reality for collaborative e-learning," Computers \& Education, 2008, (50), pp. 1339-1353.

[4] Maria Virvou, George Katsionis, "On the usability and likeability of virtual reality games for education: The case 
of VR-ENGAGE,” Computers \& Education, 2008, (50), pp. 154-178.

[5] Maria Limnioua, David Robertsb, Nikos Papadopoulos, "Full immersive virtual environment CAVE in chemistry education,” Computers \& Education, 2008, (51), pp. 584593.

[6] H. Hoyer, A. Jochheim, C. Rohrig, et al, « A multiuser virtual-reality enviroment for a tele-operated laboratory," IEEE Transaction on Education, 2004, 47(1), pp. 121-126.

[7] W. J. Book, K. Koeppen, M. Rouse, "Virtual access hydraulic experiment for system dynamics and controls education,” Mechatronics, 2002, 12, pp. 261-270.

[8] F. J. Jimenez, J. De Frutos, "Virtual instrument for measurement, processing data, and visualization of vibration patterns of piezoeletric devices," Comuter Stantards \& Interfaces, 2005, 27, pp. 653-663.

[9] C. Wang, R. X. Gao, „A virtual instrumentation system for integrated bearing conditon monitoring," IEEE TRANSACTIONS ON INSTRUMENTATION AND MEASUREMENT, 2004, 4(2), pp. 325-332.

[10] K. Yoshida, "The Space Dyn: a MATLAB Toolbox for space and mobile robots," J. of Robotics and Mechatronics, 2000, 12(4), pp. 411-416.

[11] Jianfeng Lu, Zhigeng Pan, Hai Lin, etc., "Virtual learning environment for medical education based on VRML and VTK,” Computers \& Graphics, 2005, 2(29), pp. 283-288.

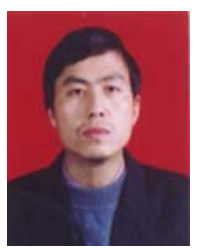

Tian-tai GUO was born in Gansu Province, P. R. China, in 1968. He received his $\mathrm{PhD}$ in the field of mechanical engineering at Zhejiang University, Hangzhou, P. R. China, in 2005.

He worked as engineer in a factory first, and became a college teacher after he got his master degree in 1998. Since 2006, he has been an associate professor of China Jiliang University, Hangzhou, P. R. China. Main publications:[1] Tiantai GUO . Virtual-environment-based Instrument Development Technology . Proc. of 16th International Conference on Artificial Reality and Telexistence (ICAT2006)[C] . 29 November - 1 December 2006. Hangzhou, China. Pp232-235..[2] Tian-tai GUO, et al. Research on VR-based virtual test technology. China Mechanical Engineering, 2003, 14(22): 1939-1942 (In Chinese).[3] Tian-tai GUO, et al. Sub-function model of VRbased virtual test technology. China Mechanical Engineering, 2008, 19(7): 812-815 (In Chinese). His main research interests are virtual reality and computer simulation.

Dr. GUO is head of Dept. of Measurement \& Control Technology and Instrumentation, China Jiliang University, Hangzhou, P. R. China. He is also a member of the Optoelectronic Technological Committee of China Aviation Society.

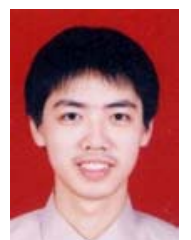

Lin GUO was born in Zhejiang Province, P. R. China, in 1984. He received his master degree in the field of precision instrumentation at China Jiliang University, Hangzhou, P. R. China, in 2008, and has been a postgraduate student of China Jiliang University ever since.

His main research interests are virtual instrument and plant physiology simulation.

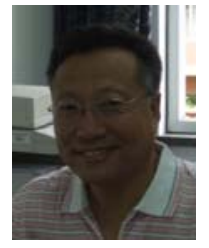

Dong-sheng LI was born in Jilin Province, P. $\mathrm{R}$. China, in 1955. He received his $\mathrm{PhD}$ in the field of precision instrumentation at Harbin Institute of Technology, Harbin, P. R. China, in 2001.

He worked as lecturer in Northeast Forestry University first, and worked as professor in China Jiliang University, Hangzhou, P. R. China, since 2002. His main research interests are precision instrumentation.

Dr. LI is head of Faculty of Metrology and Measurement Technology and Instruments in China Jiliang University, Hangzhou, P. R. China. 